\title{
Do accident and emergency patients collect their prescribed medication?
}

\author{
C. P. FREEMAN AND H. R. GULY
}

Accident and Emergency Department, The Royal Hospital, Wolverhampton, England

\section{SUMMARY}

One month's prescriptions from an accident and emergency department were examined. Of these $16 \%$ were found not to have been dispensed by the chemist. The commonest drugs prescribed were antibiotics $(60 \%)$ and analgesics $(22 \%)$. Most age groups were guilty of failing to collect drugs-primary non-compliance.

\section{METHOD}

In this department FP10 prescription forms are available for use by accident and emergency doctors at times when the hospital pharmacy is closed. The drugs are issued by the local dispensing chemist who then sends the FP10 to the prescription pricing authority. Subsequently, the month's prescriptions are returned to the Treasurer of the Health Authority for the bill to be deducted from the hospital budget. At the time of issue in the accident and emergency department a record of the FP10 number is made alongside the casualty card number. All the FP10 prescriptions returned from the month of February 1983 were examined. The type, or types, of drug prescribed and the number of the prescription were recorded. For those FP10s which were issued but not dispensed the drug, or drugs, prescribed and the age of the patient could usually be obtained from the doctor's notes on the casualty card.

\section{RESULTS}

A total of 226 FP10 prescriptions were issued from the accident and emergency department in February 1983. Of these prescriptions 36 were not cashed at the chemist.

Correspondence: Mr C. P. Freeman, Accident and Emergency Department, Dudley Road Hospital, Birmingham, England 
This gave a primary non-compliance rate of $16 \%$.

The types of drug prescribed, including those which were not cashed, is shown in $\frac{\mathbb{0}}{6}$ Table 1. Some FP10 prescriptions were for more than one drug so the total number of drugs exceeds the total number of prescriptions. Table 2 shows the age distribution of those patients guilty of primary non-compliance.

Table 1 The types of drug prescribed. The first figure is the total number of that drug prescribed, followed $\frac{\overline{\bar{N}}}{5}$ by the number of the total which were not cashed

\begin{tabular}{lcc}
\hline Drug & Total & Not cashed \\
\hline Antibiotics & 136 & 14 \\
Analgesics and non-steroidal anti- & 49 & 5 \\
$\quad$ inflammatory preparations & & \\
Decongestants and bronchodilators & 9 & 1 \\
Topical applications & 8 & - \\
Antacids & 8 & 3 \\
Expectorants & 5 & - \\
Antispasmodics & 3 & 1 \\
Antiepileptics & 3 & - \\
Antihistamines & 3 & 1 \\
Benzodiazepines & 3 & - \\
Antiemetics & 2 & - \\
Antidiarrhoeals & 1 & - \\
Antiarrhythmics & 1 & - \\
Antithyroids & 1 & - \\
Laxatives & 1 & - \\
Beta-blockers & 1 & - \\
G.T.N. & 1 & - \\
Vitamins & 1 & - \\
Miscellaneous & 1 & - \\
Unrecorded & 12 & 12 \\
\hline
\end{tabular}

Table 2 The age distribution of those patients $\left({ }^{*}\right)$ who failed to collect their prescriptions

\begin{tabular}{|c|c|c|}
\hline \multirow[t]{6}{*}{ Age: } & $0-15$ years & $* * * * * *$ \\
\hline & $16-30$ & $* * * * * * * * * * *$ \\
\hline & $31-45$ & $* * * * * * * * * *$ \\
\hline & $46-60$ & $* * * * * * * *$ \\
\hline & $61-75$ & \\
\hline & $76-90$ & * \\
\hline Age $n$ & ot recorded & ** \\
\hline
\end{tabular}

\section{DISCUSSION}

Much has been written about patient non-compliance once drugs have been collectedsecondary non-compliance. However, there is relatively little in the literature about the failure of patients to collect drugs-primary non-compliance. The only published 
articles we have found have been from general practice.

This small study gives a primary non-compliance rate for accident and emergency prescriptions of $16 \%$. One study (Rashid, 1982) has reported a primary non-compliance in general practice as high as $20 \%$, but there are large variations between practices.

A recent audit of prescriptions in a general practice (Begg, 1984) showed a $6.4 \%$ primary non-compliance rate, and another study conducted in a mining practice found that $7 \%$ of all prescriptions were not dispensed (Waters et al., 1976). Begg (1984) found that patients who were required to pay prescription charges were less likely to cash their prescription than those who were exempt.

Table 2 appears to show a greater number of non-compliants in the age range 16-45 years; however, this probably reflects the age distribution of patients attending the accident and emergency department. Without interviewing the patients concerned it is not possible to give definite reasons for primary non-compliance. Most studies show that the working man is the most likely patient to fail to collect prescribed medication. This may represent a reluctance of the 'bread winner' to incur prescription charges or to lose time from work in collecting the drugs from the chemist. It would also appear that some patients attend their general practitioner or accident and emergency department for reassurance and advice, and are less concerned with the drugs prescribed.

The system of using FP10 forms for out-of-hours prescribing is used in many, but not all, accident and emergency departments. It is an expensive method of issuing drugs and alternative ways of providing the service are being studied by this department.

We have shown that antibiotics were the commonest group of drug prescribed in the accident and emergency department at the time studied and that these were often not collected (Table 1). This was also the finding of Rashids' study (1982). Analgesics and antacids are also drugs which are frequently rejected by patients (Waters et al., 1976).

It would seem predictable that primary non-compliance is higher in the accident and emergency environment than in general practice, as the patients are seen by a doctor who is unfamiliar and who they are unlikely to see again.

It is a waste of the doctors' time giving a prescription in the accident and emergency department unless they take time to explain and justify the drugs to the patient. Patients who are not motivated to take the prescribed medicines will often avoid the expense of collecting them, particularly if they are required to pay prescription charges.

Unless a record of all prescriptions is made in the accident and emergency department as well as on the casualty card it is impossible to detect which prescriptions are not being used. All accident and emergency staff should be aware that a large proportion of patients do not collect their prescribed medication.

\section{REFERENCES}

Begg D. (1984) Do patients cash prescriptions? An audit in one practice. Fournal of the Royal College of General Practitioners 34, 272-4.

Rashid A. (1982) Do patients cash prescriptions? British Medical fournal 284, $24-6$.

Waters W. H. R., Gould N. V. \& Lunn J. E. (1976) Undispensed prescriptions in a mining general practice. British Medical fournal 1, 1062-3.

Received 17 fuly 1984; editorial comments to author 17 August 1984; accepted for publication 1 October 1984 